\title{
A New Wave of Learning in Finland : Get Started with Innovation!
}

\section{Korhonen, Tiina}

Springer

2017

Korhonen , T \& Lavonen , J 2017 , A New Wave of Learning in Finland : Get Started with Innovation! . in S Choo, D Sawch, A Villanueva \& R Vinz (eds), Educating for the 21st Century : Perspectives, Policies and Practicies from Around the World. Springer, Singapore , pp. 447-467 . https://doi.org/10.1007/978-981-10-1673-8_24

http://hdl.handle.net/10138/310836

https://doi.org/10.1007/978-981-10-1673-8_24

acceptedVersion

Downloaded from Helda, University of Helsinki institutional repository.

This is an electronic reprint of the original article.

This reprint may differ from the original in pagination and typographic detail.

Please cite the original version. 
A New Wave of Learning in Finland: Get Started with Innovation!

\author{
Tiina Korhonen \\ Head of Innokas Network \\ Department of Teacher Education, University of Helsinki \\ Prof. Jari Lavonen \\ Head of the Department of Teacher Education, University of Helsinki
}

\begin{abstract}
Author Note
Correspondence should be addressed to: Tiina Korhonen, Department of Teacher

Education, University of Helsinki, Siltavuorenpenger 5, 00014 University of Helsinki

Phone: +358504486933, Email: tiina.korhonen@helsinki.fi
\end{abstract}


A New Wave of Learning in Finland: Get Started with Innovation!

\begin{abstract}
This chapter describes the grass-roots nature of the Innokas Network and explores how networking can support teachers in adopting strategies for teaching 21 st century competence. The context for this study is the Innokas Network, a Finnish school development network. The goal of Innokas Network is to initiate educational reform for the learning of 21 st century competence as a new wave of learning arising from widespread innovation on the grass-roots level. The key question driving activities in Innokas Network is how we can teach and support the learning of 21 st century competence in practice. Innokas Network is focused on answering this question through the Innovation Education approach, within the framework provided by the Innovative School model (ISC).

To study teachers' experience with such networking, thoughts and ideas for supporting teachers in teaching of 21 st century competence were collected from Innokas Network teachers during the 2013-2014 school years. The results indicate that teachers experienced the Innovation Education approach practiced in the network, when implemented through ISC principles, such as educational innovations, peer-to-peer learning, teamwork, and partnerships, as helpful in teaching 21 st century competencies. In addition, teachers mentioned the motivational effect provided by taking part in nationwide network activity as well as the enabling effect of the limited but well-coordinated support provided by the network.
\end{abstract}




\section{Roots of the Network}

As a small country of 5.5 million inhabitants with no natural gas or oil reserves, Finland has for a long time recognized education as the country's most important natural resource. The current Finnish education system, with universal basic education in the three national languages (Finnish, Swedish, and Sami), as well as a focus on professional teachers, was built through ongoing educational reform since the 1940s (Ministry of Education and Culture, 2014; Ministry for Foreign Affairs of Finland, 2014; Sahlberg, 2011).

The general values and aims of Finnish basic education are described in the Finnish National Core Curriculum for Basic Education (NCCBE) document, published by the National Board of Education (2014). Key underlying values in Finnish education are human rights, equality, democracy, natural diversity, preservation of environmental viability, endorsement of multiculturalism, and individualism (in terms of responsibility and as part of a community). The values originate from classical and modern Western humanism. In the schools, the values are incorporated into subject matter as well as everyday activities. The core curriculum includes general, subject-specific, and cross-curricular aims and encourages the school principal, teachers, and students to engage in continuous development of school operations and in teaching and learning processes that are based on feedback and evaluation.

The Finnish educational system is decentralized; local education authorities are responsible for the provision and quality of educational services. Instead of imposing a detailed national curriculum, the national curriculum framework forms the value basis for the entire educational system. An important part of this system is the preparation of local curricula at the municipality and school levels. 
The NCCBE recently underwent its most recent review, with participants from various stakeholders addressing current and future national and global challenges and devising methods for responding to these challenges in the education system. The challenges include trends in the Finnish economy due to globalization, such as the relocation of not only production but also high-tech professional work to lower-cost countries, and the recent downturn in the oncedominant Finnish telecommunications industry. In addition, the Finnish demography is more diverse than before, with more languages and ethnic minorities, the largest of which are Russian, Estonian, and Somali.

The key contemporary theme in education reform is to find ways to help today's children learn the 21 st century competence they will need in their work and free time. These include creative and critical thinking, problem solving and inquiry skills, as well as everyday skills to navigate an increasingly technology-based society, to work in multicultural teams that cross national borders, and to innovate; to come up with novel solutions and inventions that provide students with a competitive advantage in the global market (European Union, 2006; Niemi, 2014; Organization for Economic Co-operation and Development [OECD], 2013a, 2013b).

The recent policy review is not the first review to address 21 st century competence. In the previous review in 2004, the NCCBE was amended with new cross-discipline topics on entrepreneurship ("Participating Citizenship and Entrepreneurship") and technology ("Human and Technology"). To address the need to implement the new NCCBE topics in the City of Espoo, a small group of elementary-level education professionals (five primary school teachers and one official from the local school administration) started on their own initiative brainstorming ways to incorporate the new skills into practical schoolwork. The group's work quickly gravitated toward a set of central working ideas, which today would be considered the 
core of what is now known as Innovation Education, an educational approach developed through practical network activities and associated research. These ideas were implemented as hands-on, practical projects in which students learn by creating their own innovations. What started as a small endeavor in one school has grown in 10 years into a large-scale, country-wide network of innovative schools and communities.

Early insights arising from the initiative include the realization that programming, or "coding," is a key part of 21 st century literacy and that the increasingly available robotics technology offers a practical, hands-on tool to learn the principles of coding and to express new, imaginative technological innovations. In a programming activity, students employ critical and creative types of thinking and engage in problem solving. Somewhat surprisingly, robots proved to be the key to engage girls, who normally would distance themselves more from coding and technology, resulting in displays of amazing robotic dancing performances showcasing their creativity.

In 2007, in order to share these learnings and best practices with other teachers in a peerto-peer manner, the group applied for and was granted local support in the City of Espoo as a “learning center" named "Innokas.” The learning center started arranging trainings for other teachers in Espoo and established an innovation lab space in a school. The Finnish name Innokas translates into "eager" or "pumped-up" in English and is also a word play with inno (innovation) and kas for kasvatus (education).

Soon after, Innokas networked extensively with practicing teachers in other parts of Finland, including both Finnish and Swedish speakers who were interested in school development. Innokas also established a co-operation with the Department of Teacher Education at the University of Helsinki, with the aim of performing pragmatic, design-based research 
(DBR) on the best ways to support the learning of 21 st century competence, with professional teachers as both educational innovators and active researchers (Korhonen, Lavonen, Kukkonen, Sormunen, \& Juuti, 2014).

Enabled by a grant from the National Board of Education in 2011, Innokas set up the national Innokas Network with 36 primary schools coordinated by three volunteer area coordinators, with volunteer participation by practicing professional teachers in participating schools. The network was built into its current size in three phases; the third phase in 2015 included 250 schools and 10 area coordinators. Using the volunteer workforce, the Innokas Network has arranged 40 to 50 professional training courses each year for teachers as well as four national-level Innovation Education events in 2012, 2013, 2014, and 2015 with participation by more than 2,500 primary school students, teachers, parents, and administrative and industry stakeholders interested in the teaching of 21 st century competence. Innokas Network members actively perform practical research on the learning of 21 st century competence in collaboration with the University of Helsinki and Stanford University and are contributing to national-level discussion, including the recent review of the NCCBE. The Innokas Network has also started an international collaboration with similar initiatives worldwide. Schools in Australia, the United States, Canada, China, and Finland have participated in the initial activities in the Global Innokas Network.

In this chapter, we describe the grass-roots nature of the Innokas Network and its practical and research activities, which are based on the ISC model, a model for a learning environment supporting the development of methods for learning 21 st century competence. In addition, we present an analysis of how Innokas Network participants have experienced the network's activities based on a self-evaluation by participating teachers. 


\section{Enabling the Learning of 21st Century Competence}

\section{Innovation Education}

The Innovation Education approach is defined as the combination of the crossdisciplinary Finnish traditions in handcrafts, arts; science, technology, engineering, arts, and mathematics (STEAM), and other school subjects with the methods of digital fabrication, handson learning, and technology education. Innovation education is closely related to "maker culture," an approach for learning through doing in a social environment. Maker culture is based on informal, fun, typically peer-led, and networked learning through the creation of novel applications of technology, using methods that combine traditionally separate domains such as various types of artwork with versatile working methods such as wood, metal, and textile work and digital methods like videography and computer programming (Kangas, SeitamaaHakkarainen, \& Hakkarainen, 2013; Viilo, Seitamaa-Hakkarainen, \& Hakkarainen, 2011).

In addition to encompassing the core principles of maker culture, Innovation Education expands them with school-based pedagogical approaches rooted in the long tradition of Finnish handcraft teaching. Students are guided and encouraged to use creative planning processes, to learn thinking skills, and to engage in teamwork and projects that transcend traditional boundaries between school subjects. Teachers engage in learning discussions with students on the nature of innovation and inventions and on whether each individual student could also become an inventor. In the discussions, the students also identify technological innovations that are in use in contemporary society, the changes these innovations have brought and are still bringing to society, and the opportunities for using technological innovations in the future. Students are encouraged to envision, design, and implement new innovations in a process that spans school subjects, makes use of ubiquitous technology, and applies the knowledge and skills 
students have learned in new areas (Autio \& Lavonen, 2004, 2005; Lavonen \& Autio, 2003;

Lavonen, Autio, \& Meisalo, 2004; Lavonen, Korhonen, Kukkonen, \& Sormunen, 2014).

\section{Educational Innovations}

The key concept in the implementation of the Innokas Network is the use of educational innovation in the school to enable the learning and teaching of 21 st century competence. According to Rogers (2003), an innovation is an object, idea, or practice that appears new to an individual or to a group, for educational innovations, to a group of teachers, students, or other school actors. An innovation may also be an idea that is known to the group, but which the group has not yet accepted or rejected. As entirely new ideas are rare, we also consider the modification of an existing idea an innovation. In the Innokas Network, we focus specifically on innovations concerning novel ways to use information and communication technology (ICT) to support learning and teaching of 21 st century competence.

In Innokas Network, educational innovation can manifest as Learning Innovations, which are innovations created by students and by teachers working alongside students with the purpose of learning 21 st century competence, and as Operational Innovations, which are innovations on the learning environment aimed at supporting the learning of 21 st century competence. In Innokas Network, Operational Innovations can be created by all stakeholders in the school and include new ways to use ICT in the school's organizational and pedagogical approach. Table 1 lists key attributes and examples of Learning Innovations and Operational Innovations. 
Table 1

Learning Innovations and Operational Innovations

\begin{tabular}{ll}
\hline Learning Innovations & Operational Innovations \\
\hline $\begin{array}{l}\text { Innovations created by students and teachers } \\
\text { Use creative planning processes }\end{array}$ & $\begin{array}{l}\text { Innovations on the learning environment } \\
\text { aimed at supporting the learning of 21st } \\
\text { century competence } \\
\text { Learn thinking skills }\end{array}$ \\
$\begin{array}{l}\text { Engage in teamwork and projects that cross } \\
\text { traditional boundaries between school } \\
\text { subjects }\end{array}$ & $\begin{array}{l}\text { include new ways to use ICT in the school's } \\
\text { organizational and pedagogical approach }\end{array}$ \\
$\begin{array}{l}\text { Makes use of ubiquitous technology and } \\
\text { applies the knowledge and skills students } \\
\text { have learned in new areas }\end{array}$ & \\
$\begin{array}{l}\text { Examples } \\
\text { Dancing robot, smart clothes }\end{array}$ & $\begin{array}{l}\text { Examples } \\
\text { Team teaching, break clubs organized by } \\
\text { students, student tutor model }\end{array}$ \\
\hline
\end{tabular}

\section{Participants as Innovators}

The key assumption driving the implementation of the Innokas Network is that the participation by teachers, students, school leaders, parents, and other partners in generating and implementing ideas will support their commitment to (a) original innovations and (b) adoption of innovations to suit learning contexts. This assumption is supported by research, which indicates that user involvement in innovation implementation and reinvention increases the likelihood of continued use and further development of the innovation (Rogers, 2003). In the Innokas Network, the adoption of innovations has been supported through active collaboration by the participants in common DBR projects.

\section{Innovative School}

During the creation of the Innokas Network, we faced several ICT challenges when we started innovating in order to cultivate 21 st century competence. There were issues with the 
availability of ICT equipment and network connectivity and with the suitability of work spaces and learning materials. In addition, teachers who were not accustomed to using technology in their work were afraid of the new approach. At the same time, there was a need to find solutions to day-to-day challenges, such as the need to simultaneously support personalized learning and larger group sizes, the need to manage the school's operations effectively, and the need to collaborate with parents.

Although these challenges felt overwhelming at times, we were encouraged to learn that we could come up with Organizational Innovations that addressed these challenges. As an example, when thinking about a possible way to use ICT to teach 21 st century competence, a group of teachers realized that there were not enough ICT tools in the school to implement their planned learning activity and that they needed to innovate on new ways to organize school work on the grade level through team teaching.

We soon realized that while many such challenges can be addressed with Organizational Innovations, supporting this approach requires a new, holistic look at how the school works. Through collaborative research and development work, we developed a model that describes the key factors that need to be place in a school to support the learning of 21 st century competence and the creation of educational innovations. The ISC model, illustrated in Figure 1, consists of four interdependent main factors: students' learning and learning environments, teachers' professionalism, leadership, and partnerships (Korhonen et al., 2014). 
Teachers, students, principals, parents, and other partners as innovators

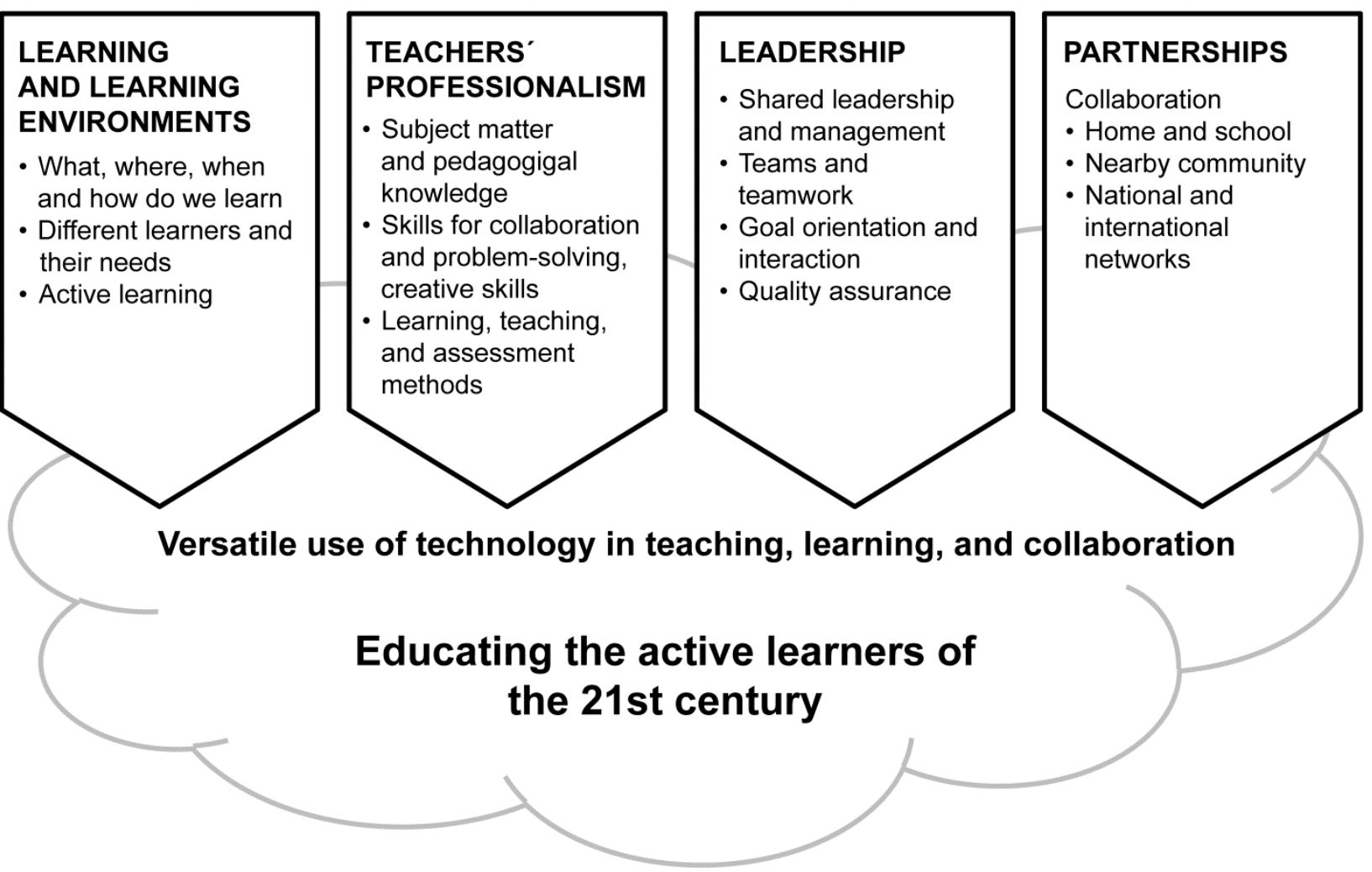

Figure 1. The Innovative School model.

A key guiding principle in the model is the comprehensive and versatile use of ICT in learning and teaching, in schools' daily operational processes, and as an enabler for educational innovation aimed at school development. In addition to teachers and the school management team, key actors in the ISC model include the school's students and other personnel, as well as individuals in the school's internal and external partnership networks. The external partnership networks include parents, local community organizations, and companies, as well as national and international networks. The ISC model emphasizes the role of all of these actors as innovators and encourages them to collaborate in planning, implementing, and further developing the 
school's activities. These development activities are ongoing, iterative, and cyclic, are based on assessment, and are aligned with the latest technological and societal development.

The learning and learning environment factors in the ISC model focus on the development of students' 21 st century competence. In the 21 st century, individuals need to be able to think critically and creatively, make use of a wide range of tools in creativity and interaction, engage, and interact in heterogeneous groups, as well as act autonomously and take responsibility for managing their own lives (Trilling \& Fadel, 2009). Due to the students' diverse backgrounds, choosing teaching and learning methods that support the learning of 21 st century competence is not straightforward. It is important to utilize a variety of teaching methods to engage students in meaningful learning. Meaningful learning is grounded in activity and intention, reflection and self-evaluation, collaboration and interaction, construction, contextualization, and cumulative learning (Donovan \& Branford, 2005). In the ISC model, meaningful learning is targeted through the cross-disciplinary approach provided by Innovation Education.

To enable the Innovation Education approach, a school implementing the ISC model also simultaneously develops the other key factors: teachers' professionalism, leadership, and partnerships. School actors review the school's activities and ways of working holistically and then improve the approaches by cultivating them through Operational Innovations. These innovations include ways to best utilize existing, limited resources such as teachers and ICT equipment to support students in learning 21 st century competence. For example, teachers can work as a team to rethink the teaching arrangements on a grade level. By first combining their resources, (for example by creating a combined group of 70 third graders and three teachers instead of three separate classes), the teachers can come up with new, flexible groupings of 
students based on the students' needs, the availability of teachers and ICT resources, as well as the requirements of the learning task.

The leaders of the school play a key role in encouraging teachers and other school personnel to start rethinking the school's operations and to support and guide the personnel in creating operational innovations. In their new role as leaders of change, the school principal and other leaders can employ shared leadership and team organization principles. To support these activities, the leaders also design and deploy new methods and structures for sharing expertise within the school (Lavonen et al., 2014).

A relatively untapped potential to support new ways to learn 21 st century competence is provided by the school's partnership networks. Local partnership networks include parents as well as local community actors, such as daycare centers and public libraries (Korhonen \& Lavonen, 2014; Kukkonen \& Lavonen, 2014a). Other partnerships include nationwide collaboration in the Innokas Network as well as participation in global collaboration networks. The use of ICT, including the use of collaboration tools and web conferencing, is a key enabler for interactions with the partners.

\section{Innokas Network}

\section{Purpose of the Initiative}

The Innokas Network aims to initiate educational reform for the learning of 21 st century competence as a new wave of learning arising from widespread innovation on the grass-roots level. The purpose of the Innokas Network is to act as an enabler for this by developing, testing and sharing best practices on Innovation Education, by arranging targeted support resources, by performing research, and arranging professional development programs for teachers within the framework of the ISC model. 
Develop and share teaching and learning practice on 21 st century competence. The key open question driving all activities in the Innokas Network is how we can teach and support the learning of 21 st century competence in practice. Based on its grass-roots origin as a development group for technology-based innovation in the school, the Innokas Network is focused on answers to this question that involve the application of technology and Innovation Education methods. The Innokas Network aims to develop best practices for Innovation Education in collaboration with teachers and students, widely test the practices within the network, and share the best practices with schools in Finland as well as globally through the Global Innokas Network.

Provide targeted support resources. In the Finnish education system, the responsibility for arranging primary education lies with individual municipalities that have strong autonomy. Aligning with this model, the Innokas Network aims to educate the communal decision-makers on the importance of Innovation Education and to guide them to find the most effective ways to support Innovation Education within their organization. With direct national-level funding, the network aims to provide enabling support that helps as many schools as possible to take part in the network.

Arrange and support professional development programs. The Finnish basic education system is based on the notion of professional teachers; all qualified in-service teachers hold university-level degrees. As a result, professional teachers and school-level leaders are allowed considerable autonomy in their classroom and school, respectively, with very little guidance from the education authorities (Krzywacki, Lavonen, \& Juuti, 2014).

In this professional environment, the success of any education reform is highly dependent on teachers and school principals being informed about the reform, agreeing with the goals of the 
reform, and having the knowledge and skills to confidently implement the reform at the grassroots level. To facilitate the success of the new wave of learning, Innokas Network aims to provide professional development programs on Innovation Education, on related school organization, and on design-based research (DBR) based educational research to both in-service teachers and student teachers.

Perform research. To guide informed decision-making on education policy reform, the Innokas Network aims to contribute towards building a body of research on the teaching and learning of 21 st century competence. The research topics include Innovation Education practices and the use of technology in schools. The research on technology use is not limited to learning technology but includes the use of technology to facilitate the creation of Operational Innovations in the school's organization, including the use of technology for breaking the traditional boundaries between home, school, and other community actors.

Educational research has been criticized for its alleged lack of impact on educational practice. As an example, the versatile use of ICT in education has not been adopted by teachers in Finland and in many other countries (European Commission, 2013; OECD, 2006). To perform research that is more applicable to practice, researchers in the Innokas Network employ DBR, an iterative research approach that emphasizes the participation of all school actors as innovators. In educational DBR, teachers take on new roles as educational researchers (Korhonen \& Lavonen, 2014; Kukkonen \& Lavonen, 2014b; Sormunen, Lavonen, \& Juuti, 2014). 


\section{Key Stakeholders}

Between 2011 and 2015, more than 45,000 persons participated in Innokas Network activities. The participants included students and teachers in Innovation Education activities in schools as part of normal schoolwork and as an extracurricular activity and teachers in professional development programs. In addition, the participants include parents, school administrators, public library personnel, university students and teachers as well as company representatives attending Innokas Network events. These stakeholders, and their role in the Innokas Network, is illustrated in Figure 2.

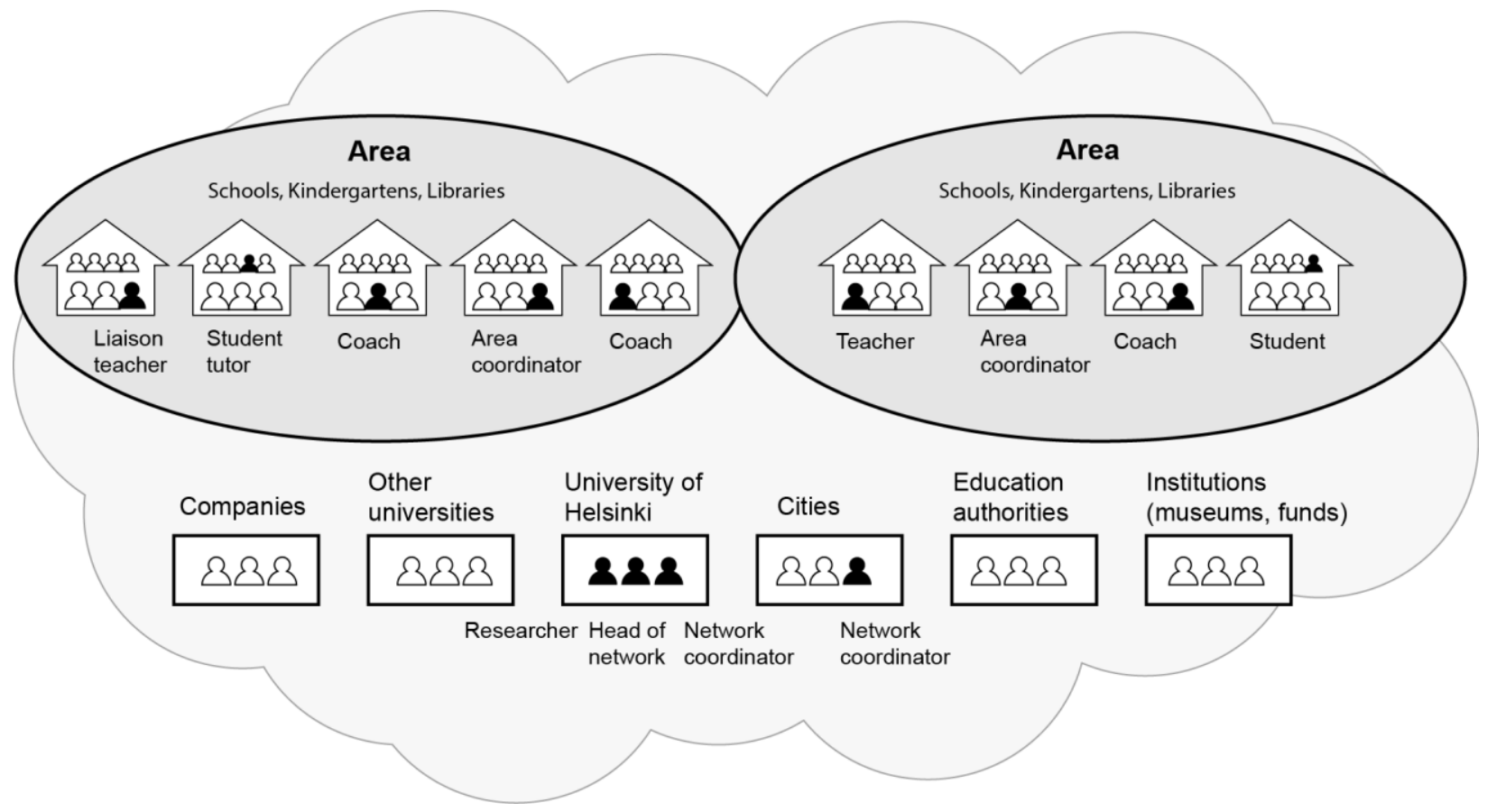

Figure 2. Structure and key stakeholders of the Innokas Network.

Participating schools. The majority of Innokas Network activities are carried out in 250 participating schools located in various regions of Finland. Each participating school nominates one to three volunteer Innokas liaison teachers who take responsibility for coordinating activities 
in the school. These liaison teachers share best practices from other Innokas Network schools within their own school, support their colleagues in the creation of innovations, share their activities on the Innokas Network's blog and encourage the school's personnel and external partners to engage with the Innokas Network. The network remains open and welcomes new participants.

Teachers. The role of professional teachers is key in the Innokas Network. Individual teachers implement Innovation Education principles in projects, tasks, and extracurricular activities within their own classrooms and in novel team organizations spanning the grade and the whole school. In this work, the teachers receive guidance, support, and encouragement from the Innokas Network. Teachers can apply Innovation Education principles not only in STEAM subjects but also in the planning and implementation of all schoolwork (Lavonen et al., 2014).

Students. In the Innokas Network, students are seen not only as receivers but also as active participants in Innovation Education and in planning and running school work. In participating schools, students regularly take up a student tutor role, guiding their peers in working with their innovations and introducing their teachers to new technology (Kukkonen \& Lavonen, 2014b).

School leaders. As Finnish schools have wide autonomy in day-to-day operations, principals and other school leaders play a key role in Innokas Network schools. School leaders do not need to endorse Innokas Network, but when they assume a positive and encouraging attitude toward improving the school's operational culture, teachers feel that there is room for their innovations for improving the school's operation to enable the learning of 21 st century competence. To help school leaders understand the opportunities for their school, Innokas Network makes an effort to keep them informed about the network's activities. 
Parents and other partners. The Innokas Network encourages parents to participate in the network and develops and tests ways for parents to collaborate with the school on the use of technology to support students' learning and growth. In addition to parents, other community stakeholders, such as public kindergartens, libraries, and museums, collaborate with the network in order to extend the school's learning environment for Innovation Education outside traditional organizational borders, enabling boundless learning (Niemi, Multisilta, \& Löfström, 2014).

The Innokas Network also collaborates closely with companies, including companies that provide technology-based educational solutions that can be tested in Innokas Network schools and companies that see 21 st century competence as a key challenge in future society and want to address this challenge in their community engagement activities.

Researchers and university/school partnerships. Research activities in the Innokas Network are carried out in close collaboration with researchers at the University of Helsinki. Research in the Innokas Network is not limited to full-time researchers; teachers are informed about the potential benefits of educational research activities and are encouraged to employ DBR principles for school development, thus becoming researchers themselves. Several Innokas Network teachers have taken further steps into research and are working on theses.

Coordinators and coaches. As a grass-roots, volunteer-based initiative, the Innokas Network runs a very lean and flexible organization without an unnecessary hierarchy that can slow down collaboration. The overall network is coordinated by the University of Helsinki in collaboration with the City of Espoo. Local activities are currently divided into 10 geographic areas (Espoo, Turku, Tampere, Lappeenranta, Kuopio, Jyväskylä, Larsmo, Kontiolahti, Oulu, and Rovaniemi), each under the responsibility of an area coordinator. Area coordinators act as lead innovators in their area, sharing information, arranging local events, coaching teachers, and 
further developing the network. As one of the areas is located in a predominantly Swedishspeaking area of Finland, the area coordinator, a Swedish-speaker himself, arranges all activities in his area in Swedish.

In addition to the area coordinators, there are 25 active coaches in the Innokas Network who coach teachers in their own school, as well as in regional and national activities in collaboration with the area coordinators. It is important to note that the area coordinators and coaches take up their respective roles in addition to their on-going work as practicing teachers. As the coordinators and coaches are intimately familiar with the day-to-day challenges in schools, the overall coordination and coaching approach remains very pragmatic and down-toearth. This method resonates well with the professional teachers who participate in the network.

The Innokas Network has assigned resources to support the area coordinators' and coaches' efforts when needed, for example, by enabling the hiring of substitute teachers to cover the coordinator's short absences or by compensating the coordinators or coaches for their additional work. Until recently, the main coordinator role has been a secondary role as well, for a school vice principal. As the network is spread out across a geographically large country, the coordinators and coaches collaborate primarily through chat, email, and virtual meetings, with face-to-face meetings arranged twice a year.

\section{Practical Activities}

As robotics and programming are new to Finnish schools, tools for supporting them may not rank high on the list of an individual school's budgeting priorities. To enable Innovation Education activities in participating schools, the Innokas Network has provided schools with key enablers for Innovation Education based on robotics and programming, including Lego MindStorms Robotics kits and training and consultation for teachers on the use of robotics in 
Innovation Education. Teachers have also participated in Innokas Network training sessions on the use of ICT tools for creating Operational Innovations. In addition, regional coordinators have organized regional activities within their own region. This regionally relevant support has been crucial to getting the schools started.

From 2012 to 2015, the Innokas Network has organized an annual national Innokas Technology Event for schools. In addition to various student and teacher workshops on Innovation Education and the use of ICT for learning 21st century competence, each event has hosted the RoboCup Junior Finnish National championship competition, where student teams from Innokas Network schools, accompanied by the robot innovations they created in Innovation Education, participate in five events (sumo wrestling, dance/theater, soccer, rescue, and freestyle). The location of this national event is intentionally rotated among regional areas (2012, Joensuu, eastern Finland; 2013, Espoo, southern Finland; 2014, Oulu, northern Finland; 2015, Joensuu, eastern Finland) in order to achieve more local visibility and to encourage more schools in the area to participate in Innokas Network. The national events are made possible by countless volunteer hours put in by network teachers and student teachers at the local university and the generous support of companies participating in Innokas Network.

In fall 2013, Finland participated for the first time in the European Union (EU) Robotics Week activities. Since then, the network has issued a yearly Robotics Week/Code Week video challenge to Finnish schools and daycare centers to participate. More than 8,000 participants took up the challenge in the first year, implementing their own activities under the Robotics Week and reporting on the activities on the Innokas Network blog. To reward those who participated in the challenge, Innokas Network arranged a drawing for three Lego Robotics kits and associated training for the participating schools and centers. 
To inform as many people as possible about the Innokas Network and Innovation Education, the network informs the media about its activities and participates in national and international education-related conferences and events, with teachers, students, and researchers from the network presenting their activities. The Innokas Network also provides information on the network web site, blog, and Twitter and Facebook accounts. On the blog, participants share stories, pictures, and videos about their Innovation Education projects as well as ideas, tips, and best practices on Innovation Education with other participants in the network and with all other interested parties. Through the blog, participants can also learn about upcoming Innokas Network events. As the blog is bilingual, with Swedish speaking schools posting in their first language, both Finnish and Swedish speakers are introduced to the bilingual nature of Finland (students start learning the other national language in the seventh grade).

Innokas Network participants are encouraged to share their ideas and suggestions for the further development of the network. An annual feedback and suggestions survey for the participants provides guidance for next year's activities.

\section{Participants' Experiences}

To learn how Innokas Network participants have experienced the network's activities, we analyzed two annual surveys (2013 and 2014) of the teachers who participate in the network. The survey data was collected using a web-based form, and the teachers' experience analyzed within the ISC framework using deductive content analysis (Elo \& Kyngäs, 2008).

Based on the survey answers (from 127 teachers divided between all geographic areas of the network), the participating teachers felt that the Innovation Education approach used in the network helps them teach 21 st century competence when teaching is implemented following the ISC principles of Innovation Education with Educational Innovations, Operational Innovations, 
peer-to-peer learning, teamwork and partnerships. In addition, the teachers mentioned the motivational effect provided by participating in nationwide network activity as well as the enabling effect of limited but well-coordinated support provided by the network.

\section{Innovation Education}

Robotics kits, with their associated programming tools, are well suited for supporting the learning of 21 st century competence. These tools are adaptable for both younger and older students and, by facilitating the implementation of students' innovations in technology use, support the development of thinking, collaboration, and teamwork skills. In contrast to solely computer-based environments for teaching programming skills that may seem abstract and less motivating, students who see the robotic innovations they have built responding to changes in their programming are often overwhelmed with enthusiasm and have no trouble learning the essential concepts of computer programming. Through Innovation Education, students learn not only to use technology but also to understand the essence of the ubiquitous technology surrounding them, which leads them to use the technology to create new things instead of fearing the unknown technology.

During the brainstorming, design, building, and practical testing of innovations, Innovation Education exposes students to pedagogical approaches such as handcrafts, research orientation, experimental learning, and playful learning, which all motivate them in learning $21 \mathrm{st}$ century competence. Teacher 21 stated:

Lego robot kits are brilliant as teaching tools in all grades in primary school [grades 1-9] and in the lower secondary school [grades 10-13]. With the kits, we can practice programming through playful learning. At the same time, we work in a team together and learn about technology. Students are interested in programming when they can actually 
build something that responds to their programming. They see what happens as a result of their programming and how the result changes with changes in programming.

\section{Operational Innovations}

A key success factor for Innokas Network has been that every participant can engage with and be an innovator in the network. Aligning with the ISC model, each school has approached network activity from its own point of view. Each actor in the network plans and implements Innokas Network activities in their various learning environments based on the actor's own local conditions, needs, and capabilities. There is no single correct way to implement Innokas Network activity. On the contrary, part of the network's success has been the variety of adaptions and different types of local activity. For example, some schools may choose to implement Innokas Network activity under one school subject while others may run the activity in projects spanning multiple subjects, as optional parts of the school curriculum, or as an extracurricular club activity run by teachers or student tutors. In addition, schools may incorporate Innokas Network activity as part of existing school activity such as theme weeks, drama, or presentation projects or as part of the planning for annual school events and festivities. Although the implementation of the activity varies from school to school, schools are expected to share their experiences with others, allowing other schools to ask if the same thing would also work in their school or, better yet, how they could adapt the activity for their own use. Teacher 48 said, "We have activity in the classrooms on all grades (in upper grades [6-9] as part of each subject), as a voluntary activity, as extra work, in projects, in school festivities, and in clubs after school and during breaks [Finnish school days have 15-min breaks every hour]." Teacher 25 commented, "In the upper grades, we have used the materials and expertise from the technology lab in handcrafts [woodand metalwork] classes." Teacher 52 said, "In our school, the focus is in our technology-oriented 
class. The teacher of that class is allocated extra hours that have enabled practically all lower grades [1-6] to get to know technology in multiple ways." Teacher 9 observed, "During the last year, we have run two clubs for fourth graders and two optional subjects for sixth graders. The clubs' innovations have been presented during school festivities."

\section{Peer-to-peer Learning}

A key practice in Innokas Network is that students and teachers are encouraged to assume new roles as peers, freeing them from the constraints of their traditional relationship where the teacher is expected to have all the answers. In the Innokas Network, a teacher does not need to be a robotics or programming expert in order to start Innovation Education activities; teachers just need to think how they can explore the area together with their students and discover the expertise they may already have in their classroom. Teachers can assume a role as the guide and facilitator of the activity, while empowering students to teach other students as well as the adults in the school. This full engagement of students, peer-to-peer learning, and the students' innovation as a key part in improving the teaching and learning of 21 st century competence in the school aligns with the principles of the Innovative School model. Teacher 22 stated:

Our school has an active technology club [for students], where we have built Lego robots, programmed games using Scratch, and discussed contemporary technology, especially mobile technology. We have also done some exploration into augmented reality. Some of the club members have guided their class in a robotics workshop.

Teacher 74 said, "We have run a [robotics] club for grades 4-6 every Thursday between 2 p.m. and 3:30 p.m. for the whole school year. In addition, the fifth-grader robotics club members have run a 'siesta club' [break club] for all students in grades 1-2." Teacher 36 observed, "During the 
Robot Week, Grade 6 students acted as assistant teachers for the whole school. All teachers and students got to work with Lego [robot kits] on four stations for a whole day."

The peer-to-peer learning approach has also been utilized in training activities organized by Innokas Network. Many of the participating schools have nominated student tutors who work as a team with the school's teachers, guiding other students and teachers in Innovation Education. These teams of teachers and student tutors have also guided participants in Innokas Network trainings and in other events. Teacher 34, "One thing that was especially successful was the common workshop between students and teachers, we want more of those."

\section{Teamwork}

In addition to the peer-to-peer learning approach, a key strength in Innokas Network is the emphasis on teamwork, with two teachers or a teacher and a teaching assistant working as a team that guides a learning activity. By having more than one adult present, the preparation of the activity (brainstorming and gathering and preparing the tools and materials), as well as the guiding of student work, becomes much easier. As they can discuss their concerns and ideas with their adult colleague, teachers find it safer to engage in a new type of activity or to start working with tools that are completely new to them. The benefits of teacher teamwork have already been recognized in the training of new student teachers, with Finnish university students working as a team to conduct their teaching practice. University teacher 1 stated:

Our student teachers take a robotics course as part of their technology education studies. They practice teacher work on grades 5-6 as well as in optional eighth-grade electronics classes. The student teachers plan and guide a 12-hour robotics course for students as pair work. 


\section{Partnerships}

The Innokas Network has benefited from its partnerships on various levels. It is essential that parents can take part in the network's activity and can learn that they also can support their children in the learning 21 st century competence by encouraging their children to continue innovating outside the school setting. Parents also play an important role in supporting Innokas Network events as additional adults guiding the students and, in some schools, as leaders of extracurricular technology clubs. Teacher 12 said, "In our area, a Lego robotics club is run by parents."

Teacher 18 said, "We participated in the regional robotics event in Kontiolahti [in eastern Finland] in December 2013 and in the Finnish [RoboCup Junior] nationals in Oulu [in northern Finland] in May. The clubs and the competition trip were organized by parents."

By expanding the learning environment beyond the traditional school boundaries and by utilizing the students' expertise outside the school setting, we can motivate students in learning 21 st century competence as well as encourage the whole community to take an interest in these skills. A key type of partnership is collaboration within the local community, for example, with the daycare center and local public libraries. Utilizing a peer-to-peer approach, Innokas Network students can guide Innovation Education activities in a daycare center or in an event arranged in a public library. Teacher 30 stated:

In our school, during the Robot Week, we ran an introductory workshop on programming and artificial intelligence for the students of the school and the daycare center/kindergarten [some of Finnish school buildings are integrated with a daycare center for 5- to 6-year-old children]. The workshop was attended by a total of 300 people, 
including members of the local press. I have also run an introduction [to the] Innokas [Network] and robotics programming for the other teachers in our school.

Teacher 49 said, "We took part in the public library day of the Robot Week under the guidance of an Innokas Network teacher and the local library personnel.”

\section{Motivation}

A key success factor in Innokas Network, accomplished by implementing the network's working principles, is the motivation, excitement, and desire to make practical things happen. Throughout the network, teachers and students not only find peer-to-peer support for their challenges but also get excited by practical examples of what others have done in Innovation Education. Teacher 41 said, "Collaboration with other schools is surely motivating students, and at least my own students got even deeper into the initiative when they saw what other schools had done and started immediately brainstorming their own robots." It is noteworthy that Innovation Education can also engage students who are normally not very interested in school work or in learning 21 st century competence. Participating in the network has also provided motivating experiences for teachers. Teacher 15 said, "A good thing about working in a classroom is that also the students who are less technology-oriented get exposed to robots — and get excited by them." Teacher 62 said, "An interesting initiative that has got the students excited. I hope we manage to spread the excitement to all the teachers in the school." Not only students and teachers but also teachers and parents are motivated. Teacher 19 observed, "It has been magnificent to notice all that joy and get positive feedback from students, teachers and parents!

We have managed to get many children motivated with the robots! (-)." Teacher 37 wrote, “Thank you! We've received lots of thanks from parents and students. I hope we can continue the [network] activity and that we can offer students these skills of the future." 
Coordination. A special success factor in Innokas Network is the grass-roots approach to network coordination, implemented through Innokas Network liaison teachers in schools and through teachers working as local area coordinators. With the strong collaboration among the coordination team, Innokas Network has managed to provide limited but well-organized support that has enabled more schools to participate and allowed the creation of locally relevant training that has supported the participating schools. Teacher 31 stated:

A very good initiative. Let's arrange a couple of days of initiation training again in the fall to get new teachers on board. The role of the [area] coordinator school is important. The major event in the spring was good, and you provided the funds that made it possible for us to join. We will absolutely continue to be part of the network.

\section{Discussion}

Based on our experiences in the Innokas Network, we suggest that Innovation Education supports the teaching and learning of 21 st century competence. By freeing teachers from the perceived need to have more expertise on technology than their students, by empowering students for peer-to-peer learning, and by motivating students who would normally not be interested in learning 21st century competence, Innovation Education provides a flexible approach for new learning challenges.

The key concept that makes Innovation Education work is educational innovation. By extending this principle outside the students' Learning Innovations to Operational Innovations involving the whole school, the school can find solutions to tough organizational issues involving the use of ICT in learning as well as issues between students or can find new ways of taking cultural differences into account in the school. In essence, educational innovation is a new way to think and work in the school. 
To enable educational innovation in a school, a holistic approach that supports innovative practices must be developed and established. The ISC model describes such an approach, emphasizing the participation of all school actors in school development, new ways of working such as team teaching, support from school leadership, the establishment of knowledge-sharing structures as well as the importance of partnering with parents and other actors outside the school as key factors that enable the emergence of educational innovation. The ISC model is based on sharing responsibility and empowering teachers and students. Thus, the school leaders' attitude is key in establishing an environment that encourages educational innovation. This enables the application of Innovation Education in the school, providing a practical approach for solving the challenge of teaching and learning 21 st century competence.

Our experience in Innokas Network suggests that a grass-roots approach to school development is beneficial but presents its own challenges. For those participating in the network, the grass-roots approach is highly motivating as the initiative is something started by their colleagues and not decided on some obscure level in the higher echelons of the school administration. As the network coordinators are practicing teachers, the planned activities are well suited for implementation as part of practical schoolwork, and the overall approach in the activities provides support for practicing teachers through practical solutions such as teacher teamwork and peer-to-peer teaching.

A key challenge with this approach is to get all teachers and schools to participate in new activity. Many teachers and schools may still be content with current practices or accustomed to waiting for somebody else to come and say what they should do. A part of this challenge is funding the new activity. Securing four to six years of uninterrupted funding to expand the network to a much larger portion of Finnish schools is challenging. An initiative aiming to solve 
the teaching of future competency is easily overwhelmed by other priorities at the local level, and continued funding should be secured at the national level.

As a grass-roots approach, Innokas Network has worked through difficulties to establish true collaboration between the various stakeholders in students' learning of 21 st century competence. To really work, collaboration must be mutually beneficial and must recognize all parties as experts who have a say in the planned activities and in the direction of the network. A network initiative such as the Innokas Network must have the audacity to push through organizational boundaries and engage schools, parents, school administration, other community actors, universities, and companies in real collaboration.

The most effective method for implementing Innovation Education or similar approaches may vary based on the national-level educational setup and tradition. In the Finnish tradition, based on independent, professional teachers who may advance to leadership positions as school principals and school administrators, the key to implementing Innovation Education is to expand the teachers' professional expertise. For in-service teachers, this is achieved through professional development programs (PDPs) designed for Innovation Education and the ISC approach.

Teachers often feel that the school administration pressures them into using some new technology, and many PDPs are arranged to train teachers on the specific technology. What we propose is that PDPs should start from an approach that sees teachers as innovators. Instead of forcing a technology on them, teachers should learn to become innovators, choosing the tools they need to support their and their students' innovations. After being offered the spark to get their fires burning, the teachers can incorporate a more research-based approach and become educational innovators for a new wave of learning. 


\section{References}

Autio, O., \& Lavonen, J. (2004). Teaching decision making through a creative and co-operative technology education course. In I. Mottier \& J. De Vries (Eds.), Pupils' decision making in technology: Research, curriculum development and assessment. Retrieved from http://www.iteaconnect.org/Conference/PATT/PATT14/Autio.pdf

Autio, O., \& Lavonen, J. (2005). Defining a process in a creative and co-operative technology education course. Journal on School Educational Technology, 2(1), 57-65.

Donovan, M., \& Branford, J. (2005). History, mathematics, and science in the classroom Committee on how people learn, a targeted report for teachers. Washington, DC: National Academic Press.

Elo, S., \& Kyngäs, H. (2008). The Qualitative Content Analysis Process. Journal of Advanced Nursing, 62(1), 107-115.

European Commission. (2013). Survey of schools: ICT in education benchmarking access, use and attitudes to technology in Europe's schools. European Commission- IP/13/341 19/04/2013.

European Union. (2006). Recommendation of the European Parliament and of the Council of 18 December 2006 on key competences for lifelong learning. 2006/962/EC. Official Journal of the European Union.

Finnish National Board of Education. (2014). Homepage. Retrieved from http://www.oph.fi/english/education

Kangas, K., Seitamaa-Hakkarainen, P., \& Hakkarainen, K. (2013). Design thinking in elementary students' collaborative lamp designing process. Journal of Design and Technology Education, 18(1), 30-43. 
Korhonen, T., \& Lavonen, J. (2014). Crossing school-family boundaries through the use of technology. In H. Niemi, J. Multisilta, \& E. Löfström (Eds.), Crossing boundaries for learning - Through technology and human efforts (pp. 37-66). Helsinki, Finland: Cicero Learning Network, University of Helsinki.

Korhonen, T., Lavonen, J., Kukkonen, M., Sormunen, K., \& Juuti, K. (2014). The innovative school as an environment for the design of educational innovations. In H. Niemi, J. Multisilta, L. Lipponen, \& M. Vivitsou (Eds.), Finnish innovations and technologies in schools - Towards new ecosystem of learning (pp. 99-114). Rotterdam, the Netherlands: Sense.

Krzywacki, H., Lavonen, J., \& Juuti, K. (2014). There are no effective teachers in Finland - Only effective systems and professional teachers. In O.-S. Tan, \& W.-C. Liu (Eds.), Teacher effectiveness: Capacity building in a complex learning era. Singapore: Centage Learning.

Kukkonen, M., \& Lavonen, J. (2014a). Crossing classroom boundaries through the use of collaboration-supporting ICT: A case study on school-kindergarten-library-senior home partnership. In H. Niemi, J. Multisilta, \& E. Löfström (Eds.), Crossing boundaries for learning - Through technology and human efforts (pp. 67-90). Helsinki, Finland: Cicero Learning Network, University of Helsinki.

Kukkonen, M., \& Lavonen, J. (2014b). Koulu, päiväkoti, ja kirjasto oman kylän verkostossa [School, Kindergarten and Library in Own Village Network]. In H. Niemi \& J. Multisilta (Eds.), Rajaton luokkahuone [The Boundless Classroom] (pp. 152-172). Jyväskylä, Finland: PS-kustannus. 
Lavonen, J., \& Autio, O. (2003). Technology education in Finland. In G. Graube, M. Dyrenfurt, \& W. Teurkauf (Eds.), Technology education: International concepts and perspectives (pp. 177-191). Frankfurt am Main, Germany: Lang.

Lavonen, J., Autio, O., \& Meisalo, V. (2004). Creative and collaborative problem solving in technology education: A case study in primary school teacher education. The Journal of Technology Studies, 30(2), 107-115.

Lavonen, J., Korhonen, T., Kukkonen, M., \& Sormunen, K. (2014). Innovatiivinen koulu [the Innovative School]. In H. Niemi \& J. Multisilta (Eds.), Rajaton luokkahuone [The Boundless Classroom] (pp. 86-113). Jyväskylä, Finland: PS-kustannus.

Ministry of Education and Culture. (2014). Education system in Finland. Retrieved from http://www.minedu.fi/OPM/Koulutus/koulutusjaerjestelmae/?lang=en

Ministry for Foreign Affairs of Finland. (2014). Studying in Finland. Retrieved from http://formin.finland.fi/public/default.aspx? contentid=244748\&contentlan=2\&culture=en -US

Niemi, H. (2014). Teachers as active contributors in quality of education: A special reference to the Finnish context. In D. Hung, K. Y. T. Lim, \& S.-S. Lee (Eds.), Adaptivity as a transformative disposition for learning in the 21st century (pp. 179-199). Singapore: Springer Singapore.

Niemi, H., Multisilta, J., \& Löfström, E. (2014). Crossing boundaries for learning - Through technology and human efforts. Helsinki, Finland: Cicero Learning Network, University of Helsinki. 
Organization for Economic Co-operation and Development. (2006). Are students ready for a technology-rich world? What PISA studies tell us [No. 54931]. Paris, France: Programme for International Student Assessment.

Organization for Economic Co-operation and Development. (2013a). PISA 2012. Results in Focus. What 15-year-olds know and what they can do with what they know. Paris, France: Author.

Organization for Economic Co-operation and Development. (2013b). Skilled for Life? Key findings from the survey of adult skills. Paris, France: Author.

Rogers, E. (2003). Diffusion of innovations (5th ed.). New York, NY: Free Press.

Sahlberg, P. (2011). Finnish lessons: What can the world learn from educational change in Finland? New York, NY: Teachers College Press.

Sormunen, K., Lavonen, J. \& Juuti, K. (2014). Crossing Classroom boundaries in science teaching and learning through the use of smartphones. In H. Niemi, J. Multisilta, \& E. Löfström (Eds.), Crossing boundaries for learning - Through technology and human efforts (pp. 91-111). Helsinki, Finland: Cicero Learning Network, University of Helsinki.

Trilling, B., \& Fadel, C. (2009). 21st century skills. San Francisco, CA: Jossey-Bass.

Viilo, M., Seitamaa-Hakkarainen, P., \& Hakkarainen, K. (2011). Supporting the technologyenhanced collaborative inquiry and design project - A teacher's reflections on practices. Teachers and Teaching, Theory and Practice, 17(1), 51-72. 